\title{
(C) OPEN ACCESS \\ Test them all; an easily diagnosed and readily treatable cause of dementia with life-threatening consequences if missed
}

\author{
Sam Nightingale, ${ }^{1}$ Benedict D Michael, ${ }^{1,2}$ Sylviane Defres, ${ }^{1,3}$ \\ Laura A Benjamin, ${ }^{1}$ Tom Solomon ${ }^{1,2}$
}

\author{
'Brain Infections Group, Institute \\ of Infection and Global Health, \\ University of Liverpool, \\ Liverpool, UK \\ ${ }^{2}$ The Walton Centre NHS \\ Foundation Trust, Liverpool, UK \\ ${ }^{3}$ Royal Liverpool and Broadgreen \\ University Hospitals, \\ Liverpool, UK
}

\section{Correspondence to}

Dr Sam Nightingale, Brain Infections Group, Institute of Infection and Global Health, University of Liverpool, Ronald Ross Building, 8 West Derby Street, Liverpool L69 7BE, UK ; s.nightingale@liv.ac.uk

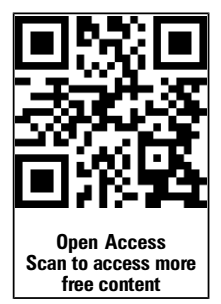

To cite: Nightingale $S$, Michael BD, Defres $S$, et al. Pract Neurol 2013;13: 354-356.
Over 90000 people in the UK are infected with HIV, a quarter of whom are unaware of their diagnosis, and the number continues to rise. ${ }^{1}$ The prognosis of HIV infection for patients on treatment is now excellent, and life expectancy approaches normal in areas with access to combination antiretroviral treatment. ${ }^{2}$ As HIV frequently leads to neurological manifestations, it is crucially important that neurologists know the indications for HIV testing, and address the barriers to testing.

We were recently involved in the care of a patient with no apparent risk factors for HIV. Multiple clinicians at several sites had made extensive investigations for isolated cognitive decline; at no point was HIV tested. A technetium-99m-HMPAO SPECT scan (figure 1) provided beautiful images but failed to identify the underlying cause. Two weeks after this scan the patient was admitted to intensive care with a fatal Pneumocystis jirovecii pneumonia associated with advanced HIV infection.

HIV enters the brain early in infection and establishes productive infection in perivascular macrophages, microglia and to some extent astrocytes. ${ }^{3} \mathrm{HIV}$-associated dementia occurs in advanced HIV disease due to several mechanisms, including neuronal damage from pro-inflammatory cytokines and toxic viral products, and loss of the homeostatic function of glia. ${ }^{4}$ It usually develops with CD4 T-cell counts below $200 / \mu \mathrm{L}$, and is an AIDS-defining condition. HIV-associated dementia is typically subcortical: there is cognitive impairment alongside prominent apathy, social withdrawal, depression and motor features, such as pyramidal slowness of fine movements, spasticity and frontal release signs. However, not all patients have these typical subcortical features, particularly early on. Before the widespread use of combination antiretroviral therapy, HIV-associated dementia was common, affecting up to $40 \%$ of HIV-infected individuals before death. ${ }^{5}$ Since treatment became available, it has become one of the few potentially reversible causes of dementia; many patients with previously marked cognitive impairment may return to independent functioning. ${ }^{6}$ Without treatment, however, life-threatening complications of AIDS usually follow 3-6 months after the dementia diagnosis. ${ }^{7}$

At present, many clinicians restrict HIV testing to those with risk factors. Clearly, they should have increased suspicion in patients from HIV-endemic regions, men who have sex with men, intravenous drug users and sex workers. However, restricting testing to these will miss cases. The HIV antibody-antigen test is a quick, cheap, non-invasive and highly reliable test that should, in our opinion, be performed in all patients presenting to neurologists with cognitive impairment. This practice is supported by the British HIV Association guidelines for HIV testing, listing dementia as a neurological indicator disease (table 1). ${ }^{8}$ Additionally, the Association of British Neurologists and British Infection Association National Encephalitis Guidelines recommend HIV testing for all patients with suspected encephalitis, regardless of perceived risk factors. ${ }^{9}$ By contrast, the UK National Institute of Health and Care Excellence (NICE) dementia guidelines currently state that the initial investigation of dementia (usually in primary care) should not include testing for HIV or syphilis, 


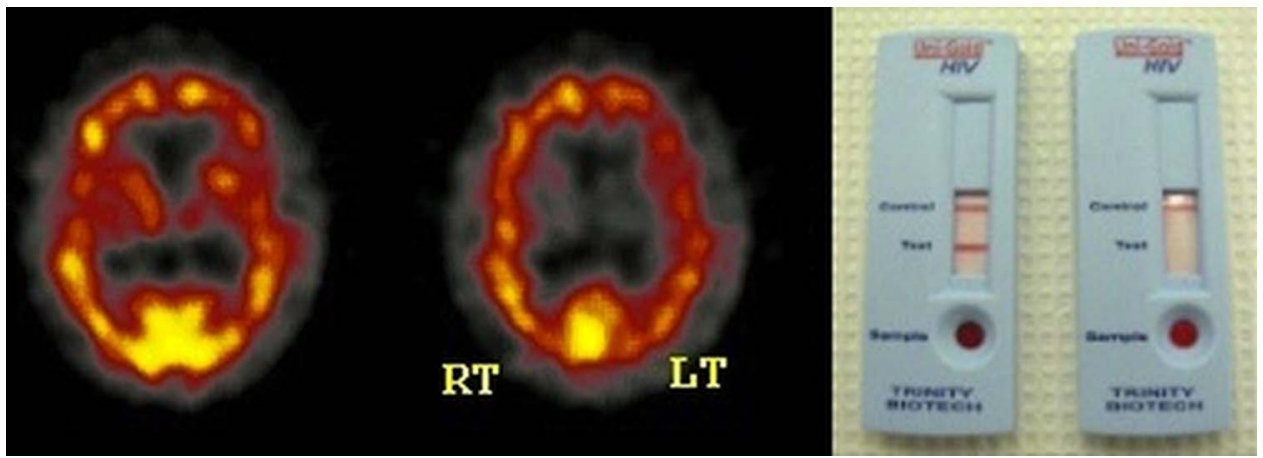

Figure 1 Left: technetium-99m-HMPAO SPECT scan showing multifocal subcortical uptake in a patient with dementia due to undiagnosed HIV infection. This sophisticated technique failed to identify the underlying cause. Right: Cheap and reliable: HIV rapid antibody finger-prick card tests ( 2 bands=positive, 1 band=negative). Most UK clinics use a laboratory-based test combining HIV antibody and the p24 antigen, costing as little as f8.

unless there are risk factors or the clinical picture dictates. ${ }^{10}$ However, the classical clinical picture is not always present. As the HIV population ages, the spectrum of disease is changing; furthermore, HIV may promote other neurodegenerative disorders, such as Alzheimer's and Parkinson's diseases. ${ }^{11}$ Also, performing HIV testing on the basis of risk factors assumes that a detailed sexual history is routinely taken, and that the answers are reliable in a person with cognitive impairment. For these reasons, we feel that HIV testing should be a routine investigation for patients with dementia presenting to neurologists.

What about an elderly woman, happily married for 50 years, who has become forgetful? We admit it has not been our practice to test routinely for HIV in this situation. However, it could be argued that HIV testing should not be restricted by age, or by our perception of the likelihood of HIV risk factors, without having explicitly asked. Although HIV is unlikely, it is not impossible. Patients do present for the first time with HIV in this age group, even without apparent risk factors. ${ }^{12}$ In the UK in 2012, $4.4 \%$ of new HIV diagnoses were aged over 60 years, ${ }^{1}$ and $\mathrm{HIV}$-associated dementia is more

Table 1 Neurological indicator diseases for HIV testing in adults, from the British HIV Association UK national guidelines for HIV testing $2008 .^{8}$

\begin{tabular}{ll}
\hline AIDS-defining conditions & $\begin{array}{l}\text { Other conditions where HIV testing } \\
\text { should be offered }\end{array}$ \\
\hline $\begin{array}{l}\text { Cerebral toxoplasmosis } \\
\text { Primary cerebral lymphoma } \\
\text { Cryptococcal meningitis }\end{array}$ & $\begin{array}{l}\text { Aseptic meningitis/encephalitis } \\
\text { Cerebral abscess } \\
\text { Space-occupying lesion of unknown } \\
\text { cause } \\
\text { Grogressive multifocal } \\
\text { leucoencephalopathy }\end{array}$ \\
& $\begin{array}{l}\text { Transverse myelitis } \\
\text { Peripheral neuropathy }\end{array}$ \\
& Dementia \\
& Leucoencephalopathy \\
\hline
\end{tabular}

common in older than in younger patients. ${ }^{13}$ In an apparently low-risk patient, HIV can be quickly and easily ruled out alongside other potentially treatable causes of cognitive impairment, such as vitamin B12/ folate deficiency and hypothyroidism. Indeed, serological testing for syphilis is still frequently performed in this situation, despite neurosyphilis being an uncommon cause of cognitive impairment at this age. ${ }^{14}$ The oldest person we have diagnosed with HIV was aged 76 years: she had no obvious risk factors and had been in an apparently monogamous marriage since her early twenties. Only on closer questioning did it emerge that her husband had died of an unusual, undiagnosed infection a few years before. His death may have been HIV-related although he was not tested-perhaps because of assumptions made about risk factors in someone of his age.

Clinicians' reluctance to offer HIV testing partly reflects the misconception that lengthy pretest counselling is needed; however, HIV testing is no different to testing for any other serious medical condition. ${ }^{8}$ If the pretest probability is low then the test needs only a brief mention; we do not counsel all smokers on the prognosis of lung cancer each time we do a chest $\mathrm{X}$-ray. Rather than entering complicated and potentially embarrassing discussions about risk behaviours, our practice is simply to inform patients that we routinely test for HIV in this situation because, although very unlikely, it is an important treatable cause. In our experience, the vast majority of patients are happy to have the test when presented in this way. This practice is consistent with guidelines from the British HIV Association, and is supported by the Royal College of Physicians. $^{8} 15$

Unlike other conditions, there is a stigma around HIV infection. Some feel that to offer a HIV test is to accuse the patient of infidelity, homosexuality or intravenous drug use. However, clinicians' embarrassment is no reason to deny a patient a potentially life-saving investigation. Considering a HIV test as a routine investigation for dementia can remove the stigma of 
the test and, moreover, avoids the need to take a detailed sexual history in all patients.

Of course, dementia is not the only neurological indication for an HIV test; table 1 gives neurological indicator diseases from the British HIV Association guidance on HIV testing. ${ }^{8}$ We believe there is growing evidence that young stroke should be added to this list. ${ }^{16}{ }^{17}$ Some go further and advocate routine screening for HIV in all hospital admissions, regardless of clinical presentation or risk group. ${ }^{18-20}$ Many parts of the USA have an opt-out strategy following recognition from the Centers for Disease Control and Prevention that targeted testing on the basis of risk behaviours was failing. ${ }^{18}$ Routine HIV testing has reduced the stigma of the test and made it more acceptable to patients. ${ }^{18}$ In the UK, several pilot studies have found this strategy acceptable and cost effective. ${ }^{1} 1920$ The Health Protection Agency (now Public Health England) recommends routine HIV testing for all general medical admissions in highprevalence areas. High prevalence is defined as $>2$ cases per 1000, a threshold exceeded by 58 local authorities in England, including Manchester, Oxford, Coventry, Brighton and Hove, Reading, Birmingham, Leeds, Leicester, Blackpool, Nottingham and 30 of the 33 local authorities in London. Indeed, in some areas of England, HIV prevalence now exceeds $1 \%{ }^{20}$

To our knowledge, there are no data on how often HIV is missed as a cause of dementia. There are estimated to be 26000 people in the UK with undiagnosed HIV infection, at risk of presenting in this way. ${ }^{1}$ The annual incidence of HIV-associated dementia in untreated cohorts from the preantiretroviral era was around $4 \%,{ }^{5}$ however, these days, many present for another reason and receive treatment before developing dementia. This requires formal study and we hope that reports such as this will focus attention and promote studies into this area. What is clear is that HIV is an easily diagnosed and readily treatable cause of dementia, but with life-threatening consequences if missed. When investigating patients with cognitive impairment, even if HIV may seem unlikely, common sense (as well as national guidance ${ }^{8}$ ) suggests that we should test them all.

Contributors SN conceived the paper. BDM, SD, LB and TS helped research and construct the argument and write the manuscript.

Funding SN is a Medical Research Council (MRC) Clinical Training Fellow supported by the North West England MRC Fellowship Scheme in Clinical Pharmacology and Therapeutics, which is funded by the MRC (grant number G1000417/94909), ICON, GlaxoSmithKline, AstraZeneca and the Medical Evaluation Unit. BDM is a National Institute for Health Research (NIHR) Doctoral Research Fellow. LAB is a Wellcome Trust Clinical PhD Fellow. TS is an MRC Senior Clinical Fellow.

\section{Competing interests None.}

Provenance and peer review Commissioned; externally peer reviewed. This paper was reviewed by Nicholas Davies, London, UK, and Jonathan Schott, London, UK.

Open Access This is an Open Access article distributed in accordance with the Creative Commons Attribution Non Commercial (CC BY-NC 3.0) license, which permits others to distribute, remix, adapt, build upon this work non-commercially, and license their derivative works on different terms, provided the original work is properly cited and the use is noncommercial. See: http://creativecommons.org/licenses/by-nc/3.0/

\section{REFERENCES}

1 Health Protection Agency (HPA). United Kingdom. New HIV diagnoses to end of December 2012. 2012.

2 van Sighem AI, Gras LA, Reiss P, et al. Life expectancy of recently diagnosed asymptomatic HIV-infected patients approaches that of uninfected individuals. AIDS 2010;24:1527-35.

3 Budka H. Neuropathology of human immunodeficiency virus infection. Brain Pathol 1991;1:163-75.

4 Navia BA, Cho ES, Petito CK, et al. The AIDS dementia complex: II. Neuropathology. Ann Neurol 1986;19:525-35.

5 McArthur JC. HIV dementia: an evolving disease. J Neuroimmunol 2004;157:3-10.

6 Cysique LA, Vaida F, Letendre S, et al. Dynamics of cognitive change in impaired HIV-positive patients initiating antiretroviral therapy. Neurology 2009;73:342-8.

7 Bouwman FH, Skolasky RL, Hes D, et al. Variable progression of HIV-associated dementia. Neurology 1998;50:1814-20.

8 (BHIVA) BHA. UK National Guidelines for HIV Testing. 2008. http://www.bhiva.org/documents/Guidelines/Testing/ GlinesHIVTest08.pdf

9 Solomon T, Michael BD, Smith PE, et al. Management of suspected viral encephalitis in adults-Association of British Neurologists and British Infection Association National Guidelines. J Infect 2012;64:347-73.

10 NICE guidelines CG42 Dementia. November 2006. http:// www.nice.org.uk/nicemedia/live/10998/30318/30318.pdf

11 Brew BJ, Crowe SM, Landay A, et al. Neurodegeneration and ageing in the HAARTera. J Neuroimmune Pharmacol 2009;4:163-74.

12 Hewitt P, Chapman C, Anand R, et al. Don't forget HIV testing in the over 60. BMJ 2011;343:d4352.

13 Ferro S, Salit IE. HIV infection in patients over 55ears of age. J Acquir Immune Defic Syndr 1992;5:348-53.

14 Zeng YL, Wang WJ, Zhang HL, et al. Neuropsychiatric disorders secondary to neurosyphilis in elderly people: one theme not to be ignored. International Psychogeriatrics/IPA 2013;25:1513-20.

15 Royal College of Physicians, Testing for HIV. Concise Guidance to Good Practice Series. http://www.rcplondon.ac.uk/sites/ default/files/testing-for-hiv-concise-guideline.pdf

16 Benjamin LA, Bryer A, Emsley HC, et al. HIV infection and stroke: current perspectives and future directions. Lancet Neurol 2012;11:878-90.

17 Benjamin LA, Joekes E, Das K, et al. Diagnostic accuracy of the Recognition of Stroke in the Emergency Room (ROSIER) score and CT brain in an HIV population. J Infect 2013.

18 Branson BM, Handsfield HH, Lampe MA, et al. Revised recommendations for HIV testing of adults, adolescents, and pregnant women in health-care settings. MMWR Recomm Rep 2006;55(RR-14):1-17; quiz CE1-4.

19 Time to test for HIV: Expanding HIV testing in healthcare and community services in England. Health Protection Agency Report, September 2011. http://www.hpa.org.uk/webc/ HPAwebFile/HPAweb_C/1316424799217

20 Evidence and resources to commission expanded HIV testing in priority medical services in high prevalence areas. Health protection Agency Report, April 2012. http://www.hpa.org.uk/ webc/HPAwebFile/HPAweb_C/1317133743551 